\title{
The Negative Sense RNA Hantavirus - A Threat to the Modern World
}

\author{
Keshani $^{1 *}$, S. S. Kanwar ${ }^{2}$
}

\begin{abstract}
Hantaviruses are rodent-borne zoonotic pathogenic viruses that produce two major clinical syndromes in humans: Hemorrhagic fever with renal syndrome (HFRS) and hantavirus pulmonary syndrome (HPS). These are negative sense RNA viruses. Each hantavirus type has a single predominant natural reservoir and is transmitted through aerosolized rodent excreta or rodent bites. Case fatality rates for HFRS can reach up to $15 \%$ and for HPS can exceed $40 \%$. Very recently, the occurrence of hantavirus has been seen in China in March, 2020. This review summarizes the current knowledge on virology, epidemiology, clinical manifestation, laboratory diagnostics, treatment, and prevention of hantaviruses and hantaviral infections.
\end{abstract}

Keywords: Hantavirus, Pathogen, Rodent

Asian Pac. J. Health Sci., (2020); DOI: 10.21276/apjhs.2020.7.2.11

\section{INTRODUCTION}

Hantaviruses are distributed worldwide, but the distribution of specific virus type is needed to be further investigated. ${ }^{[1]}$ Hantavirus is found in the urine, saliva, or droppings of infected deer mice and some other wild rodents. The virus does not remain active for long once come outside the host body usually $<1$ week and few hours when exposed to direct sunlight (www.cdc.gov/hantavirus).

Hantaviruses belong to the Bunyaviridae family of viruses that are divided into five genera: Orthobunyavirus, Nairovirus, Phlebovirus, Tospovirus, and Hantavirus. The members of this family have genomes comprised three negative-sense, singlestranded RNA segments, and hence are classified as negative sense RNA viruses. Viruses in the genus hantavirus are unique in their transmittance by aerosolized rodent excreta or rodent bites, whereas all other genera in the family are arthropodborne viruses. ${ }^{[2]}$

The name hantavirus is derived from the Hantan River, where the hantavirus (the etiologic agent of Korean hemorrhagic fever [KHF]) was first isolated by Dr. Ho-Wang Lee et al. The disease associated with hantavirus is called hemorrhagic fever with renal syndrome (HFRS) and was formerly known as KHF, or epidemic hemorrhagic fever (EHF), or nephropathia epidemica (NE). ${ }^{[3]}$ On the basis of phylogenetic origin hantaviruses are divided in two categories: Old world hantavirus causing HFRS and new world hantavirus causing hantavirus pulmonary syndrome (HPS) ${ }^{[4]}$ The former one consists of four species of hantavirus and the second one consists of the remaining (almost 24).

\section{HISTORY}

The hantaviruses constitute a relatively newly discovered genus of viruses; HFRS was first recognized by western medicine during the Korean War in the early 1950s. In 1993, a newly-recognized species of hantavirus was found as a causative agent of hantavirus cardiopulmonary syndrome (HCPS, also called HPS) caused by the Sin Nombre virus (SNV) (Spanish for "nameless virus") in New Mexico and other four corners of the states. In addition to hantavirus and SNV, several other hantaviruses have been implicated as etiologic agents for either HFRS or HCPS..$^{[5]}$
'Department of Microbiology, Punjab Agricultural University, Ludhiana, Punjab, India

2Department of Microbiology, Himachal Pradesh Agricultural University, Palampur, Himachal Pradesh, India

Corresponding Author: Dr. Keshani, Department of Microbiology, Punjab Agricultural University, Ludhiana - 141 004, Punjab, India. Email: keshani@pau.edu

How to cite this article: Keshani, Kanwar SS. The Negative Sense RNA Hantavirus - A Threat to the Modern World. Asian Pac. J. Health Sci., 2020; 7(2):42-47

Source of support: Nil

Conflict of interest: None

Received: 30/03/2020 Revised: 12/05/2020 Accepted:26/05/2020

\section{The "first" outbreak of HPS}

In May 1993, an outbreak of an unexplained pulmonary illness occurred in the Southwestern United States, in an area shared by Arizona, New Mexico, Colorado, and Utah known as "The Four Corners." A young, physically fit Navajo man suffering from shortness of breath was rushed to a hospital in New Mexico and died very rapidly. While reviewing the results of the case, medical personnel discovered that the young man's fiancee had died few days before after showing similar symptoms, a piece of information that proved key to discovering the disease. As Dr. James Cheek of the Indian Health Service (IHS) noted, "I think if it hadn't been for that initial pair of people that became sick within a week of each other, we never would have discovered the illness at all." An investigation combing the entire Four Corners region was launched by the New Mexico Office of Medical Investigations (OMI) to find out the similar case history. During this investigation, Dr. Bruce working with OMI had located five young, healthy people who died after acute respiratory failure. A series of laboratory tests had failed to identify any of the deaths as caused by a known disease. At this point, the Centers for Disease Control and Prevention (CDC) Special Pathogens Branch was notified and $C D C$, the state health departments of New Mexico, Colorado, and Utah, the IHS, the Navajo Nation, and the 
University of New Mexico all were joined together to confront the outbreak.

The particular mixture of symptoms and clinical findings pointed researchers toward some type of virus. Samples of tissue from patients who had gotten the disease were sent to CDC for analysis. Virologists at CDC after examining the samples linked the pulmonary syndrome with an unknown type of hantavirus (http:// www.cdc.gov/hantavirus/surveillance/index.html).

The carrier of this unknown hantavirus was found to be rodents with deer mouse (Peromyscus maniculatus) as the most prevalent host. ${ }^{[2]}$ Since the deer mouse often lives near human communities, researchers suspected that the deer mouse might be transmitting the virus to the humans. In November 1993, the specific hantavirus that caused the Four Corners outbreak was isolated. This new virus was called Muerto Canyon virus, which was later changed to SNV and the new disease caused by the virus was named as hantavirus pulmonary syndrome, or HPS. ${ }^{[6,7]}$

There is a recent case reported in China in March 2020, where a man died in bus tested positive for hantavirus infection. "The unidentified victim from Yunnan Province died while on a chartered bus heading to his workplace in Shandong Province, the state-run Global Times announced in a tweet." (nypost.com)

\section{Reservoir Hosts}

The main hosts of hantaviruses are rodents (www.cdc.gov/ rodents):

1. The deer mouse (P. maniculatus) is a deceptively cute animal, with big eyes and big ears. Its head and body are normally about 2-3" long, and the tail adds another 2-3" in length. You may see it in a variety of colors, from gray to reddish brown, depending on its age. The underbelly is always white and the tail has sharply defined white sides. The deer mouse is found almost everywhere in North America. Usually, the deer mouse likes woodlands, but also turns up in desert areas.

2. The cotton rat (Sigmodon hispidus), found in the Southeastern United States, has a bigger body than the deer mouse. It has head and body about 5-7" long, and another 3-4" for the tail. The hair is longer and coarser, of a grayish-brown color, even grayish-black. The cotton rat prefers overgrown areas with shrubs and tall grasses.

3. The white-footed mouse (Peromyscus leucopus) is hard to distinguish from the deer mouse. The head and body together are about 4 " long. Its tail is normally shorter than its body (about 2-4" long). Its upper side fur ranges from pale-brown to reddish-brown, while its underside and feet are white. The white-footed mouse is found through Southern New England, the Mid-Atlantic and Southern States, the Midwestern and Western States, and Mexico. It prefers wooded and brushy areas, although sometimes it lives in open grounds.

4. The rice rat (Oryzomys palustris) is slightly smaller than the cotton rat, having a head and body 5-6" long with a 4-7" long tail. Rice rat has short, soft, grayish-brown fur on top, and gray or tawny underbellies. Their feet are whitish. The rat likes marshy areas and is semiaquatic. It is found in the southeastern United States and in Central America.

5. The striped field mouse (Apodemus agrarius) is a rodent in the family Muridae. The range of this species stretches from Eastern Europe to Eastern Asia. The upper parts of the mouse are grayish brown with a rusty tint with a prominent middorsal black stripe. The under parts are paler and grayish. The ears and eyes are relatively small. The body length reaches 5", with a tail of up to $3.5^{\prime \prime}$, and it weighs up to $50 \mathrm{~g}$. It inhabits a wide range of habitats including the edges of woodlands, grasslands, marshes, pastures, gardens, and urban areas.

Each hantavirus type has a single predominant natural reservoir. Usually, the phylogenetic interrelationships among the viruses and those of their predominant host show remarkable concordance. The time and space distribution of hantavirus infection reflects the distribution and variation of their rodent hosts. ${ }^{[8,9]}$

\section{Virology}

\section{Virion Properties}

The virion is spherical or oval-shaped with $80-120 \mathrm{~nm}$ in diameter. ${ }^{[10-12]}$ It has unique grid-like surface pattern, with 7-8 $\mathrm{nm}$ projections. ${ }^{[13,14]}$ It has lipid bilayer envelope with granulofilamentous interior. ${ }^{[15]}$ It can survive for $12 \mathrm{~h}$ at $4^{\circ} \mathrm{C}$, high salt concentration and non-physiological $\mathrm{pH}$ and even survives for 1-3 days after drying. However, exposure to heat, UV irradiation, hypochlorite solutions, lipid solvents, and nonionic detergents destroys the viral envelope. ${ }^{[16]}$

\section{Genome}

Like other members of the Bunyaviridae family, hantaviruses are enveloped viruses with a genome that consists of three singlestranded, negative sense RNA segments designated as $\mathrm{S}$ (small), $M$ (medium), and $L$ (large). ${ }^{[2,17]}$ The S RNA (1.7-2.1 kb) encodes the nucleocapsid $(\mathrm{N})$ protein. The M RNA (3.6-3.7kb) encodes a polyprotein that is cotranslationally cleaved to yield the envelope glycoproteins $\mathrm{G} 1$ and $\mathrm{G} 2$. The L RNA (6.5 kb) encodes the L protein, which acts as the viral transcriptase/replicase. ${ }^{[18,19]}$ Within virions, the genomic RNAs of hantaviruses are complex with the N protein to form helical nucleocapsids, the RNA component of which circularizes due to sequence complementarity between the $5^{\prime}$ and 3 ' terminal sequences of genomic segments.

Entry into host cells is thought to occur by attachment of virions to cellular receptors and their subsequent endocytosis. Nucleocapsids are introduced into the cytoplasm by $\mathrm{pH}$-dependent fusion of the virion with the endosomal membrane. Transcription of viral genes is initiated by association of the $L$ protein with nucleocapsids. The viral $L$ protein is thought to have an endonuclease activity that cleaves cellular mRNAs for the production of capped primers used to initiate transcription of viral mRNAs. As a result of this "cap snatching," the mRNAs of hantaviruses are capped and contain non-templated 5' terminal extensions. The glycoproteins (G1 and G2) after forming heterooligomers are transported to golgi complex. The $L$ protein produces nascent genomes through replication by a positive-sense RNA intermediate. Hantavirus virions are assembled by association of nucleocapsids with glycoproteins embedded in the membranes of the Golgi, followed by budding into the Golgi cisternae. Nascent virions are then transported in secretory vesicles to plasma membrane and then released by exocytosis. ${ }^{[15,20-26]}$

\section{Properties of components involved}

Integral membrane glycoproteins, namely, MeG1 and G2 (highly conserved) weigh 64-67 kDa and 54 kDa, respectively. The G1-G2 
heterodimers form $8 \mathrm{~nm}$ projections on virion surface. These are cysteine-rich and contain asparagine-linked sugar groups. The proteins play an important role in cell entry and pathogenesis. Nucleocapsid protein $\mathrm{N}$ weighs $48 \mathrm{kDA}$ and complexes with genomic vRNA as well as with cRNA after infection, but not with mRNA. It is necessary for virus replication and packaging. Polymerase L weighs $247 \mathrm{kDA}$. It is a RNA-dependent RNA polymerase (RdRp) and complexed with ribonucleocapsids in virion. It has endonuclease activity to cleave host mRNA, transcriptase activity for making cRNA and mRNA from vRNA and helicase activity to unwind vRNA during transcription. ${ }^{[27-31]}$

\section{Transcription}

Viral polymerase transcribes negative-strand vRNA to mRNA. Polymerase acts as endonuclease and cleaves host mRNAs about 7-18 nucleotides from the 5 ' cap. The capped oligonucleotides act as primers required to initiate transcription. After transcription is primed and the first repeat of the terminal sequence is transcribed, polymerase slips and realigns the nascent RNA and then continues transcription.

\section{Replication}

Viral polymerase transcribes antisense vRNA to sense cRNA. cRNA is used as template to make more negative-strand vRNA. pppG is used to prime cRNA and vRNA synthesis using the same "prime and realign" strategy.

\section{Complete Replication Cycle}

For attachment viral G1 and G2 glycoproteins interact with cell surface receptors. Pathogenic hantaviruses bind b3 integrins and non-pathogenic hantaviruses bind b1 receptors. Virus particles bound to integrin receptors are taken in by receptor mediated endocytosis. ${ }^{[32]}$ Newly formed vesicles are acidified. Acidic environment changes conformation of G1 and G2 glycoproteins. Viral and cell membrane fuse releasing genomic material and polymerase into the cytoplasm.

After this, primary transcription occurs that transcribes negative sense vRNA to mRNA. Viral polymerase (RdRp) transcribes nucleoprotein-coated vRNA. Capped oligonucleotides from cell's own mRNA are used to prime transcription that follows the "prime and realign" model. $L$ and $S$ segment mRNA is translated on free ribosomes in cytoplasm. M segment mRNA translated on ER-bound ribosomes. $\mathrm{G} 1$ and $\mathrm{G} 2$ peptides produced from $\mathrm{M}$ mRNA are cleaved cotranslationally. Separate signal sequences for $\mathrm{G} 1$ and G2 cause ER attachment and embed the peptides in ER membrane (Signal Hypothesis).

During replication vRNA is used as a template by viral polymerase to make sense strand CRNA. CRNA is used as a template to make more negative strand vRNA. Extra vRNA synthesized during replication is used as template to make mRNA during secondary transcription. Since more template is present after VRNA is replicated, more mRNA can be transcribed, and more viral proteins can be made.

In the course of virion assembly, membrane-bound G1 and G2 peptides are transported to Golgi and carbohydrates are attached by $\mathrm{N}$-linked glycosylation. vRNA complexes with $\mathrm{N}$ nucleopcapsid protein, forms looped panhandle structure, and complexes with L polymerase. Nucleocapsid complexes bud into the Golgi membrane with $\mathrm{G} 1$ and $\mathrm{G} 2$ embedded and virion particle is formed inside the Golgi. Virions are transported to cell membrane by vesicles and released by exocytosis. Viruses may prefer different cell surfaces for release.

\section{Pathogenesis}

Hantavirus infection is more prominent in males as compare to females, with a M:F ratio of 2:1-3:1, with most of the cases occurring within the 20-40 age group. The pathogenesis of hantavirus infections is unclear. The primary replication site is not clear, in both HFRS and HPS, but the main effect is observed in blood vessels. It has been demonstrated that some pathogenic hantavirus enters cells through beta-3 integrins, which are present on the surfaces of endothelial cells, macrophages, and platelets; ${ }^{[32,33]}$ however, a study showed that beta-3 integrins did not play an essential role for respiratory epithelial cell monolayer integrity. ${ }^{[34]}$ There is increased vascular permeability and decreased blood pressure due to endothelial dysfunction. The hallmark feature of hantaviral infections is capillary leak. In HFRS, the maximum damage occurs in kidneys, and in HPS, lungs and spleen are most affected parts.

\section{Hantavirus and Host Cells}

Virus replication usually stops host macromolecule synthesis; however, hantavirus replication does not affect host cell's natural functions and moreover, hantavirus release does not require host cell lysis. Hantavirus is able to establish a persistent infection in rodent host cells. ${ }^{[1]}$

\section{Laboratory Diagnosis of Hantavirus}

Hantavirus is difficult to culture, so morphological identification is difficult. The most practical approach for the laboratory diagnosis of hantavirus infection is based on serologic tests. ${ }^{[35,36]}$ The three structural proteins of hantaviruses ( $\mathrm{Gn}, \mathrm{Gc}$, and N) can induce a high level of IgM antibodies, which are detectable at the onset of symptoms. ${ }^{[37]}$ The plaque reduction neutralization test is considered to be most effective serological test and it can be used to discriminate between different species of hantavirus. An reverse transcription-polymerase chain reaction $(\mathrm{PCR})$ using primers for conserved genome regions also allows confirmation of infection. PCR product can be sequenced and compared to known viral sequence database for species identification.

\section{Hantavirus Pulmonary Syndrome/HPS}

It is mostly found in North and South America. This disease is characterized by symptoms that resemble the flu, followed by respiratory failure and is not contagious. ${ }^{[38]}$

Hantavirus has probably caused people to get sick for years in the United States, but it was not recognized until 1993 after an outbreak of fatal respiratory illness. Hantavirus is carried by rodents, particularly deer mice, and is present in their urine and feces. The virus does not cause disease in the carrier animal. Humans are thought to become infected when they are exposed to contaminated dust from the nests or droppings of mice.

The initial symptoms of HPS closely resemble the flu. The disease begins abruptly with fever, chills, muscle aches, headache, nausea, vomiting, and malaise. A dry cough may be present. After a day or two an increased respiratory rate caused by seepage of 
fluid into the lungs occurs. The initial shortness of breath is subtle but progression is rapid. The clinical course of HPS is divided into three periods: The febrile prodrome, cardiopulmonary stage, and convalescence.

There is a 14-17-day incubation period after exposure followed by the prodrome phase typically lasting 3-6 days with myalgia, malaise, and fever of abrupt onset in the absence of cough and coryza. Other early symptoms include gastrointestinal disturbance, headache, and chills.

The febrile phase of SNV-induced HPS is followed by a cardiopulmonary phase characterized by acute onset of pulmonary edema. At this stage, cough is generally present, and gastrointestinal manifestations may dominate the clinical presentations. ${ }^{[39]}$

Tachypnea, tachycardia, and postural hypotension are typical, whereas chest examination is not impressive. Like HFRS, the most common hematologic abnormalities at the late phase of HPS are thrombocytopenia and leukocytosis. The patient ultimately develops respiratory failure. ${ }^{[40]}$ An effective treatment for hantavirus is not yet available. Even with intensive therapy, more than half of the diagnosed cases have been fatal.

\section{Hemorrhagic Fever with Renal Syndrome/HFRS}

HFRS refers to a group of clinically similar diseases that occur throughout Europe and Asia. It includes several diseases that formerly had other names, including KHF, EHF, and NE.

During HFRS an incubation phase of $2-3$ weeks followed by the onset of flu-like symptoms, lasting 3-5 days occurs. Hemorrhaging can occur during this time. Next is hypotensive phase that usually lasts from hours to days. Nausea and vomiting are common in this phase of the disease and about one-third of the patients die due to shock, and vascular leakage. Sometimes renal failure also occurs that is characterized as oliguric phase. However, in next phase, patients show improved renal functions and it takes about weeks to months for the complete recovery of patient, this final phase is known as convalescent phase.

These symptoms can be split into five phases:

- Febrile phase: This is the first phase lasting for 3-7 days. The symptoms include fever, chills, malaise, headaches, nausea, abdominal and back pain, respiratory, and gastrointestinal problems.

- Hypotensive phase: This phase can past for 2 days and occurs when the blood platelet level drops that lead to tachycardia and hypoxemia.

- Oliguric phase: This phase pasts for 3-7 days and is characterized by the onset of renal failure and proteinuria.

- Diuretic phase: This is characterized by diuresis of 3-6 L/day, which can last for a couple of days to weeks.

- Convalescent phase: In this phase, recovery occurs and symptoms begin to improve.

\section{Treatment}

There is no specific treatment or cure for hantavirus infection. Treatment of patients with HPS remains supportive in nature. Patients should receive appropriate, broad-spectrum antibiotic therapy while awaiting confirmation of HPS. Patients presenting with fulminant illness due to HPS have a poor prognosis despite ICU care. If there is high suspicion of HPS, patients should be immediately transferred to an emergency department for close monitoring and care. Fluids should be administered carefully due to the potential for capillary leakage. Supplemental oxygen should be administered if patients become hypoxic. Equipment and materials for intubation and mechanical ventilation should be readily available since onset of respiratory failure is usually fast.

Intravenous ribavirin, a guanosine analog, is not effective for the treatment of HPS though it is found effective for HFRS. Controlled trials showed a reduction in case-fatality for HFRS patients treated with ribavirin. However, ECMO - Extra Corporeal Membrane Oxygenation is used for HPS. ${ }^{[4]]}$

\section{Tests for the disease include}

- $\quad$ CBC (will show elevated white blood count)

- $\quad$ Platelet count (will be $<150,000$ and decreasing)

- X-ray of the chest (will show material invading the lungs, involving both lungs)

- $\quad$ Liver enzymes (lactate dehydrogenase will be elevated)

- $\quad$ Serum albumin (levels will be decreased)

- Hematocrit (will be increased, showing an increase in the levels of red blood cells).

\section{Prevention}

Rodent's urine and feces exposure should be avoided. During hiking and camping, the tents should be pitched in areas without rodent droppings. Keeping a clean home diminishes the chances of contacting hantavirus by clearing out potential nesting sites and maintaining a clean kitchen. ${ }^{[42,43]}$

The recommendations of U.S. CDC must be followed:

1. While opening an unused cabin, shed, or building, all the doors and windows must be opened, and the space must be allowed to air out for $30 \mathrm{~min}$.

2. After returning to the building, the surfaces, carpet, and other areas must be sprayed with a disinfectant and the building must be left for another additional $30 \mathrm{~min}$.

3. Mouse nests and droppings should be sprayed with $10 \%$ solution of chlorine bleach or equivalent disinfectant, and allowed to sit for $30 \mathrm{~min}$, using rubber gloves the material should be placed in plastic bags, sealed, and disposed of. The gloves and cleaning materials should also be disposed of in the same manner.

Vacuuming should be avoided until the area has been thoroughly decontaminated and should only be done (the first few times) with adequate ventilation.

\section{BIOTERRORISM}

According to the U.S. CDC, bioterrorism is the deliberate release of viruses, bacteria, toxins, or other harmful agents to cause illness or death in people, animals, or plants. Biological agents can be spread through air, water, or food; have specific latent time and are extremely difficult to detect. Under CDC classification HFRS causing strains are Category A because of high infectivity and morbidity. HPS causing strains are Category $C$ because of low infectivity.

There are certain considerations of pathogens for use in bioterrorism which include:

1. Health effects

a. HFRS has medium lethality however HPS is highly lethal

b. HFRS has some success with antiviral treatments whereas for HPS no effective treatment is available 
2. Epidemiology

a. Hantavirus takes medium incubation time to cause secondary infections

b. It has rodent as a vector and can spread through aerosols

3. Aerosolization

a. Virus can only be infectious for 1-3 days outside a host because of a weak lipid envelope

b. The number of particles needed to cause a human infection is not known

4. Cost effectiveness

The resources would be required to successfully disseminate hantavirus in a large population:

a. Preparation of virus using cell culture

b. Aerosolization

c. Contaminated water

d. Creation of infected rodent population

5. Psychological effects

a. HFRS causes dramatic visual effects in patients

b. HPS would be especially difficult to diagnose outside of its normal range

c. Media coverage is as "super flu" or "hemorrhagic fever"

6. Economic impact
a. Treatment
b. Disruption of work
c. Hysteria.

Hantavirus can prove as a good terrorist weapon as there is no cure for HPS infection and there is fairly long incubation period between infection and onset of symptoms. It is difficult to diagnose HPS and it has high lethal rate. However, it has low infectivity, difficult production, and less stability.

\section{VACCINES}

Vaccines against hantaviral infections have been used for years in China and the Republic of Korea. ${ }^{[44,45]}$ Some of the used vaccines are:

a. Escherichia coli expressed truncated nucleocapsid as an immunogen

b. Naked DNA

c. Recombinant non-pathogenic virus

d. Rodent brain-derived

e. Cell culture derived

f. Inactivated virus. ${ }^{[46]}$

\section{Conclusion}

With the advancing years the understanding and recognition of hantaviral infections through the world is increasing. Though newly detected, Hantavirus is an old disease. These are negative sense RNA viruses with a rodent as a natural reservoir and are transmitted through their excreta or bites. There is a long way to go to find an effective treatment for hantavirus infections. Prevention can be partially achieved by rodent avoidance, but real protection will require a safe and effective multivalent vaccine or a vaccine adapted to local conditions.

\section{References}

1. Bi Z, Formenty PB, Roth CE. Hantavirus infection: A review and global update. J Infect Dev Ctries 2008;2:3-23.
2. Lednicky JA. Hantavirus: A short review. Arch Pathol Lab Med 2003;127:30-5.

3. Vapalahti O, Mustonen J Lundkvist A, Henttonen $\mathrm{H}$, Plyusnin A, Vaheri A. Hantavirus infections in Europe. Lancet Infect Dis 2006;3:653-752.

4. Vinh DC, Embil JL. Hantavirus pulmonary syndrome and colon: A concise clinical review. South Med J 2009;102:620-5.

5. Lee HW, Lee PW, Johnson KM. Isolation of the etiologic agent of Korean hemorrhagic fever. J Infect Dis 1978;137:298-308.

6. Levis S, Morzunov SP, Rowe JE, Enria D, Pini N, Calderon G, et al. Genetic diversity and epidemiology of Hantaviruses in Argentina. J Infect Dis 1998;177:529-38.

7. Padula PJ, Rossi CM, Valle MO, Martínez PV, Colavecchia SB, Edelstein $A$, et al. Development and evaluation of a solid-phase enzyme immunoassay based on Andes Hantavirus recombinant nucleoprotein. J Med Microbiol 200;49:149-55.

8. Hart CA, Bennett M. Hantavirus infections: Epidemiology and pathogenesis. Microbes Infect 1999;1:1229-37.

9. Suzan G, Giermakowski JT, Marce E, Suzan-Azpiri H, Armien B, Yates TL. Modeling Hantavirus reservoir species dominance in high seroprevalence areas on the Azuero Peninsula of Panama. Am J Trop Med Hyg 2006;74:1103-10.

10. Hung T, Chou ZY, Zhao TX, Xia SM, Hang CS. Morphology and morphogenesis of viruses of hemorrhagic fever with renal syndrome (HFRS). I. Some peculiar aspects of the morphogenesis of various strains of HFRS virus. Intervirology 1985;23:97-108.

11. McCormick JB, Sasso DR, Palmer EL, Kiley MP. Morphological identification of the agent of Korean haemorrhagic fever (Hantaan virus) as a member of the Bunyaviridae. Lancet 1982;8275:765-8.

12. Schmaljohn CS, Dalrymple JM. Analysis of Hantaan virus RNA: Evidence for a new genus of bunyaviridae. Virology 1983;131:482-91.

13. Martin ML, Lindsey-Regnery H, Sasso DR, McCormick JB, Palmer E. Distinction between Bunyaviridae genera by surface structure and comparison with Hantaan virus using negative stain electron microscopy. Arch Virol 1985;86:17-28.

14. White JD, Shirey FG, French GR, Huggins JW, Brand OM, Lee HW. Hantaan virus, aetiological agent of Korean haemorrhagic fever, has Bunyaviridae-like morphology. Lancet 1982;8275:769-71.

15. Antic $D$, Wright KE, Kang CY. Maturation of Hantaan virus glycoproteins G1 and G2. Virology 1992;189:324-8.

16. Kraus AA, Priemer $C$, Heider $H$, Kruger DH, Ulrich R. Inactivation of Hantaan virus-containing samples for subsequent investigations outside biosafety level 3 facilities. Intervirology 2005;48:255-61.

17. Vapalahti $O$, Kallio-Kokko $H$, Narvanen A, Julkunen I, Lundkvist A, Plyusnin A, et al. Human B-cell epitopes of Puumala virus nucleocapsid protein, the major antigen in early serological response. J Med Virol 1995;46:293-303.

18. McCaughey C, Hart CA. Hantavirus. J Med Microbiol 2000;49:587-99.

19. Schmaljohn CS, Hooper JW. Bunyaviridae: The viruses and their replication. In: Knipe DM, Howley PM, Griffin DE, Lamb RA, Martin MA, Roizman B, Straus SE, editors. Fields Virology. $4^{\text {th }}$ ed., Vol. 2. Philadelphia, PA: Lippincott Williams and Wilkins; 2001. p. 1581-602.

20. Mackow ER, Gavrilovskaya IN. Cellular receptors and hantavirus pathogenesis. Curr Top Microbiol Immunol 2001;256:91-115.

21. Markotic AL, Hensley K, Daddario K, Spik K Anderson K, Schmaljohn C. Pathogenic Hantaviruses elicit different immunoreactions in THP-1 cells and primary monocytes and induce differentiation of human monocytes to dendritic-like cells. Coll Antropol 2007;31:1159-67.

22. Raftery MJ, Kraus AA, Ulrich R, Kruger DH, Schonrich G. Hantavirus infection of dendritic cells. J Virol 2002;76:10724-33.

23. Spiropoulou CF. Hantavirus maturation. Curr Top Microbiol Immunol 2001;256:33-46.

24. Ravkov EV, Nichol ST, Peters CJ, Compans RW. Role of actin microfilaments in black creek canal virus morphogenesis. J Virol 1998;72:2865-70.

25. Ruusala A, Persson R, Schmaljohn CS, Pettersson RF. Coexpression of 
the membrane glycoproteins $\mathrm{G} 1$ and $\mathrm{G} 2$ of Hantaan virus is required for targeting to the Golgi complex. Virology 1992;186:53-64.

26. Schmaljohn CS. Molecular biology of Hantaviruses. In: Elliot RM, editor. The Bunyaviridae. New York: Plenum Press; 1996. p. 63-90.

27. Panganiban AT, Mir MA. Bunyavirus N: elF4F surrogate and capguardian. Cell Cycle 2009;8:1332-7.

28. Ramanathan HN, Jonsson CB. New and old world Hantaviruses differentially utilize host cytoskeletal components during their life cycles. Virology 2008;374:138-50.

29. Severson $W E, X u X$, Jonsson CB. cis-Acting signals in encapsidation of Hantaan virus S-segment viral genomic RNA by its N protein. J Virol 2001;75:2646-52.

30. Taylor SL, Frias-Staheli N, Garcia-Sastre A, Schmaljohn CS. Hantaan virus nucleocapsid protein binds to importin alpha proteins and inhibits tumor necrosis factor alpha-induced activation of nuclear factor kappa B. J Virol 2009;83:1271-9.

31. Srikiatkhachorn A, Spiropoulou CF. Vascular events in viral hemorrhagic fevers: A comparative study of dengue and Hantaviruses. Cell Tissue Res 2014;355:621-33.

32. Song JW, Song KJ, Baek LJ, Frost B, Poncz M, Park K. In vivo characterization of the integrin beta3 as a receptor for Hantaan virus cellular entry. Exp Mol Med 2005;37:121-7.

33. Larson RS, Brown DC, Ye C, Hjelle B. Peptide antagonists that inhibit Sin Nombre virus and Hantaan virus entry through the beta3-integrin receptor. J Virol 2005;79:7319-26.

34. Rowe RK, Pekosz A. Bidirectional virus secretion and nonciliated cell tropism following Andes virus infection of primary airway epithelial cell cultures. J Virol 2006;80:1087-97.

35. Bayard V, Kitsutani PT, Barria EO, Ruedas LA, Tinnin DS, Muñoz C, et al. Outbreak of Hantavirus pulmonary syndrome. Los Santos, Panama, 1999-2000. Emerg Infect Dis 2004;10:1635-42.

36. Kruger DH, Figueiredo LT, Klempa B, Song JW. Hantaviruses globally emerging pathogens. J Clin Virol 2014;64:128-36.

37. Figueiredo LT, Moreli ML, Borges AA, Figueiredo GG, Souza RLM,
Aquino VH. Diagnosis of Hantavirus relies on demonstration of immune response, which becomes evident within 2 to 8 days of acute onset. Braz J Med Biol Res 2008;41:596-9.

38. Mattar S, Guzman C, Figueiredo LT. Diagnosis of Hantavirus infection in humans. Expert Rev Anti Infect Ther 2015;13:939-46.

39. Hallin GW, Simpson SQ, Crowell RE, James DS, Koster FT, Mertz GJ, et al. Cardiopulmonary manifestations of Hantavirus pulmonary syndrome. Crit Care Med 1996;24:252-8.

40. Raboni SM, Rubio G, Borba LD, Zeferino A, Skraba I, Goldenberg S, et al. Clinical survey of Hantavirus in southern Brazil and the development of specific molecular diagnosis tools. Am J Trop Med Hyg 2005;72:800-4.

41. Huggins JW, Hsiang CM, Cosgriff TM, Guang MY, Smith JI, Wu ZO, et al. Prospective, double-blind, concurrent, placebocontrolled clinical trial of intravenous Ribavirin therapy of hemorrhagic fever with renal syndrome. J Infect Dis 1991;164:1119-27.

42. Childs JE, Kaufmann AF, Peters CJ, Ehrenberg RL. Hantavirus infection-Southwestern United States: Interim recommendations for risk reduction. Centers for Disease Control and Prevention. MMWR Recomm Rep 1993;42:1-13.

43. Mills $J \mathbf{N}$. Regulation of rodent-borne viruses in the natural host: Implications for human disease. Arch Virol Suppl 2005;19:45-57.

44. Chen HX, Luo ZZ, Zhang JJ; Hantavirus Vaccine Efficacy Evaluation Working Group. Large scale field evaluation on vaccines of hemorrhagic fever with renal syndrome in China. Chin J Epidemiol 2002;23:145-7.

45. Dong GM, Han L, An Q, Liu WX, Kong Y, Yang LH. Immunization effect of purified bivalent vaccine to haemorrhagic fever with renal syndrome manufactured from primary cultured hamster kidney cells. Chin Med J (Engl) 2005;118:766-8.

46. Noh JY, Cheong HJ, Song JY, Kim WJ, Song KJ, Klein TA, et al. Clinical and molecular epidemiological features of hemorrhagic fever with renal syndrome in Korea over a 10-year period. J Clin Virol 2013;58:11-7. 